\title{
THREAT OF COVID-19 AND PERCEIVED STRESS: THE MEDIATING ROLE OF CHALLENGE, UNCONTROLLABILITY AND STRESSFULNESS
}

\author{
Ahmad Bilal, Minahil Aamir \\ The Islamia University of Bahawalpur, Bahawalpur Pakistan
}

\begin{abstract}
Objective: To find out the mediating role of challenge, uncontrollability, and stressfulness in predicting perceived stress from threat during COVID-19 pandemic in the general public.

Study Design: Cross-sectional survey.

Place and Duration of Study: Bahawalpur City, from Mar to May 2020.

Methodology: A total of 360 participants (men=154, women=206) were recruited from different cities of Punjab province. The stress appraisal measure, perceived stress scale, and coping scale were administered through Google forms using social media platforms. The participation in the online survey implied signing the written informed consent available in the survey.

Results: The primary and secondary appraisals of challenge (IE $=0.84, \mathrm{SE}=0.27,95 \% \mathrm{LL}=0.31,95 \% \mathrm{UL}=1.40)$, uncontrollability (IE=1.03, SE=0.36, 95\% LL=0.34, 95\% UL=1.76), and stressfulness (IE=-0.28, SE=0.12, 95\% LL=-0.56, 95\% UL=-0.08) fully mediated the relationship between threat of COVID-19 and perceived stress. Additionally, there was statistically significant positive relationship between threat of COVID-19 and use of coping strategies $(\mathrm{r}=0.14, p<0.01)$. The statistics of women regarding appraisals of threat, uncontrollability, stressfulness and perceived stress $(2.94 \pm 0.88)$; $(2.49 \pm 0.84)$; (2.87 \pm 0.73$)$; $(19.92 \pm 6.08)$, were found to be slightly higher on as compared to men $(2.76 \pm 0.82) ;(2.25 \pm 0.81) ;(2.58 \pm 0.76)$; (18.41 \pm 5.37$)$ respectively with $p=0.01$, Cohen's $\mathrm{d}=0.21) ; p=0.001$, Cohen's $\mathrm{d}=0.29) ; p=0.001$, Cohen's $\mathrm{d}=0.38) ;(p=0.01, \mathrm{Cohen}$ 's $\mathrm{d}=0.26)$.

Conclusion: The threat of COVID-19 significantly led to the experience of perceived stress through the mediating role of primary and secondary appraisals of challenge, uncontrollability, and stressfulness.
\end{abstract}

Keywords: Challenge, Coping, COVID-19, Gender differences, Perceived stress, Primary appraisal, Secondary appraisal, Stress appraisal.

How to Cite This Article: Bilal A, Aamir M. Threat of COVID-19 and Perceived Stress: The Mediating Role of Challenge, Uncontrollability and Stressfulness. Pak Armed Forces Med J 2021; 71(5): 1571-1576. doi: https://doi.org/10.51253/pafmj.v71i5.4332

This is an Open Access article distributed under the terms of the Creative Commons Attribution License (https://creativecommons.org/licenses/by-nc/4.0/), which permits unrestricted use, distribution, and reproduction in any medium, provided the original work is properly cited.

\section{INTRODUCTION}

The World Health Organization (WHO) declared COVID-19 the sixth Public Health Emergency of International Concern (PHEIC) on 30th January 2020. The experience with previous outbreaks in the world informs that both developed and developing countries can become hotspots of an outbreak at anytime. The number of cases of COVID-19 has been on rise rapidly since the detection of first case in the Pakistan. ${ }^{2}$ This has also caused a sense of alarm and threat in people throughout the country. ${ }^{3}$ Besides, the changes in living patterns and social support systems brought by COVID-19 pandemic caused people to experience stressful psychological outcomes.

Pakistan's 24/7 active news channels are aggravating the stressfulness of COVID-19 pandemic ${ }^{3}$. Additionally, the worldwide lockdown and quarantine situation further strengthened the sense of threat among people. High levels of perceived threat from the new

Correspondence: Dr Ahmad Bilal, Department of Applied Psychology, The Islamia University of Bahawalpur, Bahawalpur Pakistan Received: 20 Mar 2020; revision received: 16 Aug 2020; accepted: 20 Aug 2020 disease COVID-19 can lead to perceived stress. ${ }^{4,5}$

The environmental stress leads to the use of stress appraisal. Stress appraisal refers to the evaluation of nature and available resources to cope with the stressful situation found in the environment. The stress appraisal is an initial mechanism in using coping strategies to combat environmental stress. The stress appraisal happens at two stages. In primary appraisal, the environmental situation is evaluated for threat and challenge whereas the secondary appraisal involves the analysis of available resources. A primary appraisal of threat or challenge may lead to the experience of stress and use of coping strategies if followed by negative secondary appraisal. ${ }^{6,7}$ The pandemics in social settings cause community members feel a challenging situation. ${ }^{4}$

The appraisal of threat and challenge further leads people to use strategies to cope with the new disease. It was found that perceptions of threat, controllability and challenge of stressful situations led people to use more emotional and behavioral coping strategies such as people did during SARS outbreak ${ }^{8}$. Yang and Chu et al, ${ }^{9}$ found that perceived risk and threat of 
virus led people to experience more stressfulness and negative emotions. People are more likely to use negative coping strategies in times of an outbreak. ${ }^{10}$

Although, many studies are being conducted on various aspects of COVID-19, the studies regarding the psychological aspects of COVID-19 are scarce..$^{5}$ In this study, the cognitive appraisal model, ${ }^{6,7}$ was employed to study the role of stress appraisal in making the people perceive the stress associated with COVID-19. It was assumed that appraisal of threat is associated with making people perceive the stress of COVID-19 through the mediating effects of appraisals of challenge, uncontrollability, and stressfulness. Moreover, the study aimed to find out the relationship of threat and perceived stress with use of coping strategies. Further, the study also aimed to find out gender differences in perceived stress, primary and secondary appraisals, and coping strategies.

\section{METHODOLOGY}

A cross sectional was conducted at Bahawalpur through Google Forms based online survey from March to May 2020. After approval form Research Ethics Committee (REC-B/G1-41/2020). The online survey contained the written informed consent. The participation in the survey implied the informed consent. The written informed consent contained a description about the confidentiality of the research.

A total of 360 adults participated in the online survey designed to assess the impact of COVID-19 related threat. This sample size was calculated using an online sample calculator ${ }^{11}$, based on number of adult population in Punjab province ${ }^{12}$, with $95 \%$ con-fi dence interval and 5\% margin of error. These adults were recruited consecutive sampling from the different cities of Punjab province.

Inclusion Criteria: The adults living in Punjab province having age $\geq 18$ years were included in the online survey.

Exclusion Criteria: The adults more than 18 years of age and those living in other provinces were excluded from the study.

The online survey contained the demographic information checklist and three scales namely Stress Appraisal Measure, Perceived Stress Scale, and Coping Scale.The demographic data included age, gender, education, profession, and marital status of the participants. The stress appraisal measure is a 28 item, selfreported, 5 point likert type scale consisting of $7 \mathrm{sub}$ scales designed to assess the cognitive appraisal of the environmental stress. The subscales can be grouped into 3 categories, primary appraisal subscales, secondary appraisal subscales and a subscale to assess overall stressfulness of the situation ${ }^{13}$. The primary appraisal subscales are: Threat, challenge and centrality while the secondary appraisal subscales are: controllable by self, controllable by others and uncontrollability. Each subscale has 4 items in the scale. The internal consistency of subscales ranged from 0.73-0.86 Cronbach Alpha.

The perceived stress scale is a self-report measure in a 5 point likert type format. The scale assesses the feelings and thoughts of a person after the exposure to a stressful situation during the last month. The higher scores indicate higher perceived stress. The Cronbach Alpha internal consistency of the scale ranged from 0.84-0.86 in three different samples ${ }^{14}$.

The coping scale is a self-report 4 point likert type measure containing 13 items designed to assess the coping responses in a stressful situation. The higher scores indicate increased use of coping strategies. The internal consistency of the scale is 0.91 Cronbach Alpha. ${ }^{15}$

The data was analyzed Statistical Package of Social Sciences (SPSS) version 22 and Process Macro v 3.5. The frequencies of demographic variables were calculated for categorical data. The correlation analysis of all study variables and mediation analysis were performed. The t-test was computed to find gender differences in primary and secondary appraisal, perceived stress and coping strategies. The $p$-value $\leq 0.05$ was considered significant.

\section{RESULTS}

There were 360 participated in the study. Around $266(74 \%)$ participants were in the age group of $18-25$ years and around $46(13 \%)$ were in the age group of 26-35 years. There were equal number of participants $24(6.7 \%)$ each from the age groups of $36-45$ and $46-55$. Around 206 (57\%) women participated in the study compared to around 154 (43\%) men. The majority 216 (60\%) of the participants had bachelors education followed by $62(17 \%)$ participants with masters education and $48(13 \%)$ participants with M.Phil/ PhD education. The majority 236 (66\%) participants were students and there were only $31(9 \%)$ participants who were Health Care Professionals (HCPs). The majority participants $268(74 \%)$ were single compared to $88(24 \%)$ married participants shown in Table-I. 
Table-I: Frequency distribution of demographic variables $(n=360)$.

\begin{tabular}{l|c|c|c}
\hline $\begin{array}{l}\text { Demographic } \\
\text { Variables }\end{array}$ & Characteristics & $\mathbf{n}$ & $\%$ \\
\hline \multirow{4}{*}{ Age } & $18-25$ & 266 & 73.9 \\
\cline { 2 - 4 } & $26-35$ & 46 & 12.8 \\
\cline { 2 - 4 } & $36-45$ & 24 & 6.7 \\
\cline { 2 - 4 } & $46-55+$ & 24 & 6.7 \\
\hline \multirow{4}{*}{ Gender } & Men & 154 & 42.8 \\
\hline \multirow{4}{*}{ Education } & Women & 206 & 57.2 \\
\cline { 2 - 4 } & Inter or Less & 34 & 9.4 \\
\cline { 2 - 4 } & Bachelors & 216 & 60.0 \\
\cline { 2 - 4 } & Masters & 62 & 17.2 \\
\hline \multirow{4}{*}{ Profession } & MPhil/PhD & 48 & 13.3 \\
\cline { 2 - 4 } & Public Sector & 32 & 8.9 \\
\cline { 2 - 4 } & Private Sector & 27 & 7.5 \\
\cline { 2 - 4 } & Health Care Professional & 31 & 8.6 \\
\cline { 2 - 4 } & Other professions & 34 & 6.4 \\
\hline \multirow{3}{*}{ Marital Status } & Single & 268 & 74.4 \\
\cline { 2 - 4 } & Married & 88 & 24.4 \\
\cline { 2 - 4 } & Divorced & 4 & 1.1 \\
\hline
\end{tabular}

Table-II gives the correlations among perceived stress, primary and secondary appraisals, and coping skills. There is a statistically significant positive corre- lation between threat and perceived stress $(\mathrm{r}=0.38$, $p<0.01$ ), and between threat and coping skills ( $\mathrm{r}=0.14$, $p<0.01)$. There is no significant relationship between perceived stress and coping skills $(\mathrm{r}=-0.03, p=0.50)$. There is a statistically significant positive relationship of threat with challenge $(\mathrm{r}=0.18, p<0.01)$, uncontrollability $(\mathrm{r}=0.60, p<0.01)$, and stressfulness $(\mathrm{r}=0.71, p<0.01)$.

The results of mediation analysis of challenge, controllability, and stressfulness have been outlined in Table-III. The bootstrapping analyses with 10000 samples revealed a significant indirect effect of threat on perceived stress via challenge, uncontrollability, and stressfulness ( $\mathrm{LL}=0.75, \mathrm{UL}=2.47)$. Results based on 10000 bootstrapped samples indicated that the total effect of threat on perceived stress was also significant $(\mathrm{DE}=0.97, \mathrm{SE}=0.49, p=0.04)$. Challenge, uncontrollability, and stressfulness fully mediated the relationship between threat and perceived stress respectively $(\mathrm{IE}=$ $0.28, \mathrm{SE}=0.12, \mathrm{LL}=-0.56, \mathrm{UL}=-0.08) ;(\mathrm{IE}=0.84, \mathrm{SE}=0.27$, $\mathrm{LL}=0.31, \mathrm{UL}=1.40)$; and (IE=1.03, $\mathrm{SE}=0.36, \mathrm{LL}=0.34$, UL =1.76). The participants who indicated high levels of threat were more likely to experience challenge, uncontrollability, and stressfulness; and through these medi-

Table-II: Correlations among perceived stress, stress appraisals, and coping skills $(\mathrm{n}=360)$.

\begin{tabular}{|c|c|c|c|c|c|c|c|c|c|c|}
\hline Parameters & $\begin{array}{c}\text { Pearson } \\
\text { Correlation }\end{array}$ & $\begin{array}{l}\text { Perceived } \\
\text { Stress }\end{array}$ & Threat & Challenge & Centrality & CBS & CBO & \begin{tabular}{|c|}
$\begin{array}{c}\text { Uncontroll- } \\
\text { able }\end{array}$ \\
\end{tabular} & $\begin{array}{l}\text { Stress- } \\
\text { fulness }\end{array}$ & Coping \\
\hline \multirow[t]{2}{*}{$\begin{array}{l}\text { Perceived } \\
\text { Stress }\end{array}$} & $\begin{array}{c}\text { Pearson } \\
\text { Correlation }\end{array}$ & 1 & $0.38^{* *}$ & -0.07 & $0.31^{* *}$ & $-0.18^{* *}$ & $-0.10^{*}$ & $0.36^{* *}$ & $0.33^{* *}$ & -0.03 \\
\hline & $p$-value & - & 0.001 & 0.13 & 0.01 & 0.01 & 0.04 & 0.001 & 0.001 & 0.50 \\
\hline \multirow[t]{2}{*}{ Threat } & $\begin{array}{c}\text { Pearson } \\
\text { Correlation }\end{array}$ & $0.38^{* *}$ & 1 & $0.18^{* *}$ & $0.68^{* *}$ & $0.22^{* *}$ & $0.18^{* *}$ & $0.60^{* *}$ & $0.71^{* *}$ & $0.14^{* *}$ \\
\hline & $p$-value & 0.001 & - & 0.001 & 0.001 & 0.001 & 0.001 & 0.001 & 0.001 & 0.001 \\
\hline \multirow[t]{2}{*}{ Challenge } & $\begin{array}{c}\text { Pearson } \\
\text { Correlation }\end{array}$ & -0.07 & $0.18^{* *}$ & 1 & $0.45^{* *}$ & $0.64^{* *}$ & $0.58^{* *}$ & $0.18^{* *}$ & $0.38^{* *}$ & $0.24^{* *}$ \\
\hline & $p$-value & 0.13 & 0.001 & - & 0.001 & 0.001 & 0.001 & 0.001 & 0.001 & 0.001 \\
\hline \multirow[t]{2}{*}{ Centrality } & $\begin{array}{c}\text { Pearson } \\
\text { Correlation }\end{array}$ & $.31^{* *}$ & $0.68^{* *}$ & $0.45^{* *}$ & 1 & $.34^{* *}$ & $0.30^{* *}$ & $0.46^{* *}$ & $0.66^{* *}$ & $0.22^{* *}$ \\
\hline & $p$-value & 0.001 & 0.001 & 0.001 & - & 0.001 & 0.001 & .001 & 0.001 & 0.001 \\
\hline \multirow[t]{2}{*}{$\begin{array}{l}\text { Controllable } \\
\text { by self }\end{array}$} & $\begin{array}{c}\text { Pearson } \\
\text { Correlation }\end{array}$ & $-0.18^{* *}$ & $0.22 * *$ & $0.64^{* *}$ & $0.34^{* *}$ & 1 & $0.67^{* *}$ & 0.10 & $0.39^{* *}$ & $0.31^{* *}$ \\
\hline & $p$-value & 0.001 & 0.001 & 0.001 & 0.001 & - & 0.001 & 0.05 & 0.001 & 0.001 \\
\hline \multirow[t]{2}{*}{$\begin{array}{l}\text { Controllable } \\
\text { by others }\end{array}$} & $\begin{array}{c}\text { Pearson } \\
\text { Correlation }\end{array}$ & $-0.10^{*}$ & $0.18^{* *}$ & $0.58^{* *}$ & $0.30^{* *}$ & $0.67^{* *}$ & 1 & $0.13^{*}$ & $0.34^{* *}$ & $0.25^{* *}$ \\
\hline & $p$-value & 0.04 & 0.001 & 0.001 & 0.001 & 0.001 & - & 0.01 & 0.001 & 0.001 \\
\hline \multirow[t]{2}{*}{ Uncontrollable } & $\begin{array}{c}\text { Pearson } \\
\text { Correlation }\end{array}$ & $0.36^{* *}$ & $0.60^{* *}$ & $0.18^{* *}$ & $0.46^{* *}$ & 0.10 & $0.13^{*}$ & 1 & $0.51^{* *}$ & 0.07 \\
\hline & $p$-value & 0.001 & 0.001 & 0.001 & 0.001 & 0.05 & 0.01 & - & 0.001 & 0.18 \\
\hline \multirow[t]{2}{*}{ Stressfulness } & $\begin{array}{c}\text { Pearson } \\
\text { Correlation }\end{array}$ & $0.33^{* *}$ & $0.71^{* *}$ & $0.38^{* *}$ & $0.66^{* *}$ & $0.39 * *$ & $0.34^{* *}$ & $0.51^{* *}$ & 1 & $0.17^{* *}$ \\
\hline & $p$-value & 0.001 & 0.001 & 0.001 & 0.001 & 0.001 & 0.001 & 0.001 & - & 0.001 \\
\hline \multirow[t]{2}{*}{ Coping } & $\begin{array}{c}\text { Pearson } \\
\text { Correlation }\end{array}$ & -0.03 & $0.14^{* *}$ & $0.24^{* *}$ & $0.22^{* *}$ & $0.31^{* *}$ & $0.25^{* *}$ & 0.07 & $0.17^{* *}$ & 1 \\
\hline & $p$-value & 0.50 & 0.001 & 0.001 & 0.001 & 0.001 & 0.001 & 0.18 & 0.001 & - \\
\hline
\end{tabular}

$C B S=$ Controllable by self; $C B O=$ Controllable by others ${ }^{*} p<0.05 ;{ }^{* *} p<0.01$ 
ators, more likely to experience perceived stress. Because zero was not in the $95 \%$ confidence interval of IE, the IE was significantly different from zero at $p<0.05$.

Table-IV gives the results of $\mathrm{t}$-test computed to find out gender differences in primary and secondary appraisals, perceived stress and coping strategies. There were statistically significant gender differences in threat, uncontrollability, stressfulness and perceived stress. The result of appraisals of threat, uncontrollability, stressfulness and perceived stress of women (2.94 $\pm 0.88)$; $(2.49 \pm 0.84) ;(2.87 \pm 0.73)$; $(19.92 \pm 6.08)$ were found to be slightly higher and as compared to men (2.76 \pm 0.82$) ;(2.25 \pm 0.81) ;(2.58 \pm 0.76) ;(18.41 \pm 5.37)$ respectively, although the effect sizes were small for all significant variables $p=0.01$, Cohen's $\mathrm{d}=0.21$ ); $p=0.001$, Cohen's d=0.29); $p=0.001$, Cohen's $\mathrm{d}=0.38) ;(p=0.01$, Cohen's d=0.26). appraisals and stressfulness were more likely to perceive stress. The mediation analysis confirms this hypothesis. A recent survey research indicated that stress and anxiety increased in people in times of COVID-19 as reported by Limcaoco et al,16 involving 891 participants from 25 countries during March 2020. Similarly, Roy et al, conducted an online survey using Google forms in India and got responses from 662 adult people. The survey reported that nearly half of the respondents felt panic and threatened by the media coverage of COVID-19 cases, the same study reported that around $72 \%$ participants reported being worried due to COVID-19 pandemic. ${ }^{4}$

Threat is a primary appraisal which we use to make sense of the environment.6,7 If we appraise the situation as threatening, then the secondary appraisals are made. The secondary appraisal of uncontrollability tells us that the situation is out of control for us. It is

Table-III: Results of mediation analyses (with Process, v3.5).

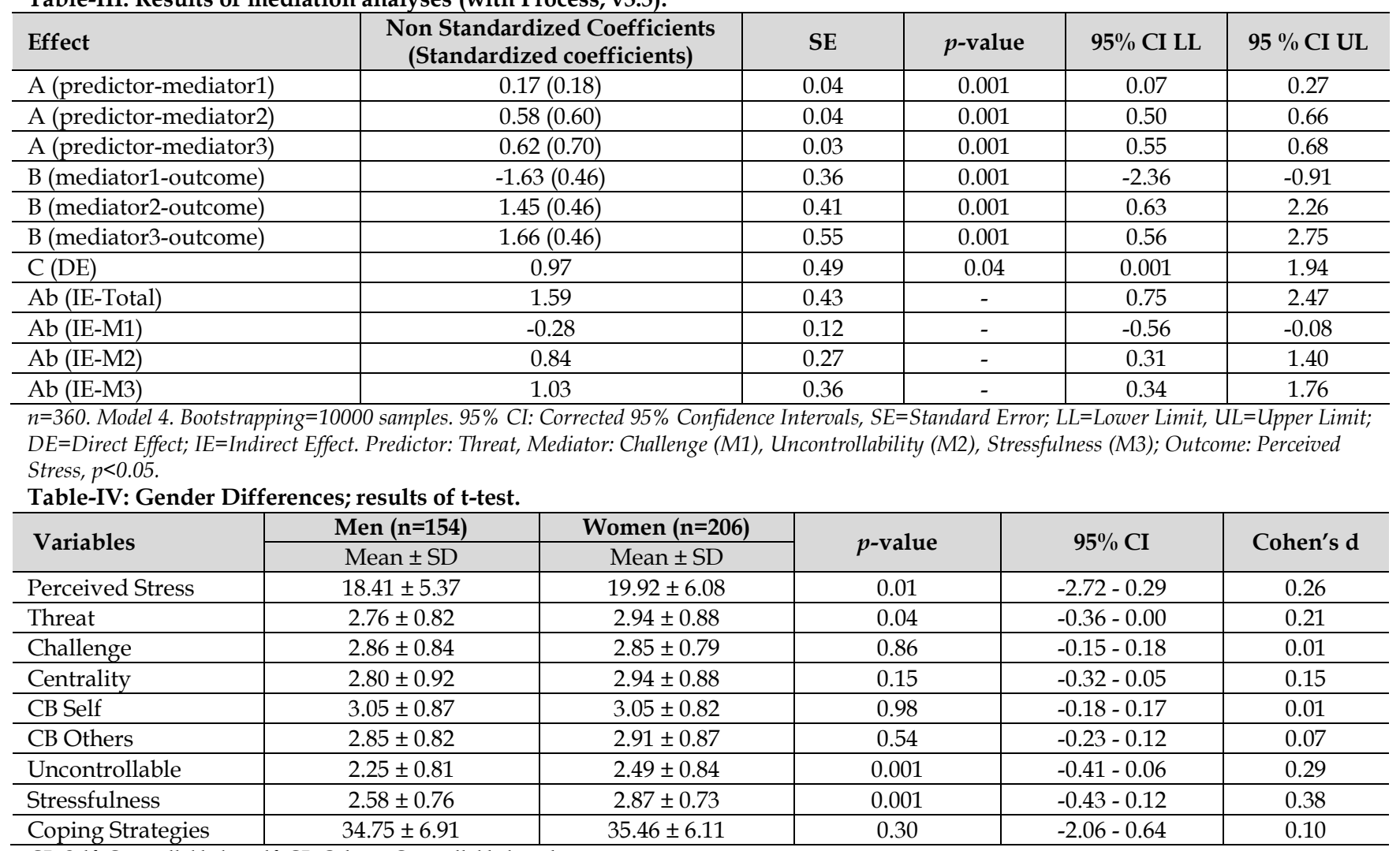

$C B$ Self: Controllable by self; $C B$ Others: Controllable by others

\section{DISCUSSION}

The current study aimed to find out the mediating role of primary and secondary appraisals in making people perceive stress in times of COVID-19. It was assumed that people who perceived more threat from COVID-19 and employed the primary and secondary through these primary and secondary appraisals that we perceive stress about COVID-19. Making a primary and secondary appraisal is normal cognitive mechanism when we experience any environmental stressor. When we find the situation threatening, it may lead to the activation of other related appraisals including 
challenge, uncontrollability and stressfulness which make the situation as stressful.

The COVID-19 is a new and novel coronavirus and little is known about its pathogenesis and mechanism of action. ${ }^{1}$ The previous research with outbreaks tells us that we become more likely to be stressful when confronted with new diseases about which little is known as reported by Fischhoff et al. ${ }^{17}$ Further, the media reporting of deadly impact of COVID-19 including mortality statistics made this new disease a source of environmental threat in Pakistan as reported by Mukhtar in a recent publication. ${ }^{3}$ The threat may lead to evaluating the situation as challenging and eventually uncontrollable, thus leading to the experience of stressfulness which ultimately results in perceived stress. ${ }^{16,18}$ The recent study by Vicario-Merino et al reported the increased incidence of both stress and anxiety in a sample of 147 Spanish residents during lockdown. ${ }^{18}$ Similar results had been reported by Limcaoco et al, in a survey study conducted in 25 countries with 891 participants. ${ }^{16}$

The correlation analyses reveal a significant positive relationship between threat and coping skills but not between perceived stress and coping skills. The people who appraise the situation as threatening, challenging and out of control become more likely to use more coping skills in the form of emotional and behavioral coping strategies as reported by famous American theorist Lazarus and Tomaka et al.6,7 However, the current study did not report a significant relationship between perceived stress and coping skills, although, the stressfulness was positively correlated with coping skills. It is through the use of cognitive appraisal of stressfulness that people start employing coping skills in stressful situations. 6,7

The present study also found statistically significant gender differences in threat, uncontrollability, stressfulness, and perceived stress. The women were found to experience more environmental threat as compared to men. Understandably, women were found to be high in uncontrollability, stressfulness, and perceived stress, although the Cohen's d represented the small effect sizes. The recent study by Kangxing with 3088 Chinese adults found female gender as one of the risk factors for experience of perceived stress during COVID-19 pandemic ${ }^{19}$.

\section{ACKNOWLEDGMENTS}

We acknowledge the original contribution of the participating study population. Without their participation, the present research had not been possible.

\section{LIMITATION OF STUDY}

The study sample was recruited only from Punjab province. The people from other provinces should have been included in the sample. The study did not differentiate between emotional and behavioral coping strategies used by participants in the analysis.

\section{CONCLUSION}

The study concludes that the appraisal of environmental situation as threatening, challenging, and stressful leads to the experience of perceived stress and results in increased use of coping strategies. The females were found slightly more likely than males to experience the appraisals of threat, uncontrollability, stressfulness and perceived stress. The modifiable sources of environmental stress like $24 / 7$ sensational reporting of COVID-19 cases need to be rationalized. The general public should have access to COVID-19 related mental health hotline at district level so as to get free counseling services.

\section{Conflict of Interest: None.}

\section{Authors' Contribution}

AB: Conceptualization \& design, data analysis, reviewing of important intellectual content, final approval.

MA: Conceptualization, design, acquisation of data, drafting, final approval.

\section{REFERENCES}

1. Lai CC, Shih TP, Ko WC, Tang HJ, Hsueh PR. Severe acute respiratory syndrome coronavirus 2 (SARS-CoV-2) and coronavirus disease-2019 (COVID-19): The epidemic and the challenges. Int J Antimicrob Agents 2020; 55(3): 105924.

2. Government of Pakistan. Coronavirus in Pakistan: Confirmed Cases, [Internet] Available from: http://covid.gov.pk. (Accessed April 30, 2020).

3. Mukhtar S. Mental Health and Emotional Impact of COVID-19: Applying Health Belief Model for Medical Staff to General Public of Pakistan. Brain Behav Immun 2020; 87(2): 28-29.

4. Roy D, Tripathy S, Kar SK, Sharma N, Verma SK, Kaushal V. Study of knowledge, attitude, anxiety \& perceived mental healthcare need in Indian population during COVID-19 pandemic. Asian J Psychiatr 2020; 51(2): 102083.

5. Ho CS, Chee CY, Ho RC. Mental Health strategies to combat the psychological impact of COVID-19 beyond paranoia and panic. Ann Acad Med Singap 2020; 49(3): 155-160.

6. Lazarus RS. Progress on a cognitive-motivational-relational theory of Emotion. Am Psychol 1991; 46(8): 819-834.

7. Tomaka J, Blascovich J, Kibler J, Ernst JM. Cognitive and physiological antecedents of threat and challenge appraisal. J Pers Soc Psychol 1997; 73(1): 63-72.

8. Dorfan NM, Woody SR. Danger appraisals as prospective predictors of disgust and avoidance of contaminants. J Soc Clin Psychol 2011; 30(2): 105-132.

9. Yang JZ, Chu HR. Who is afraid of the Ebola outbreak? The influence of discrete emotions on risk perception. J Risk Res 2018; 21(7): 834-853.

10. Lu S, Tian B, Yang T, Chen D. Analysis of the related behavioral influencing factors on the public health during SARS outbreak. Modern Prev Med 2008; 35(15): 2907-2909. 
11. Fluid Surveys University. Survey Sample Size Calculator. [Internet] Available at: http://fluidsurveys.com/university/ survey-sample-size-calculator/ (Accessed Feb 29, 2020).

12. Wikipedia, The free encyclopedia. 2017 Census of Pakistan. [Internet] Available at: https://en.wikipedia.org/wiki/2017_ Census_of_Pakistan (Accessed Feb 29, 2020).

13. Peacock EJ, Wong PTP. The stress appraisal measure (SAM): A multidimensional approach to cognitive appraisal. Stress Med 1990; 6(3): 227-236.

14. Cohen S, Kamarck T, Mermelstein R. A global measure of perceived stress. J Health Soc Behav 1983; 24(4): 385-396.

15. Hamby S, Grych J, Banyard VL. Life Paths measurement packet: Finalized scales. Life Paths Research Program 2015. [Internet] Available at: http://www.lifepathsresearch.org/strengthsmeasures. (Accessed Feb 29, 2020)
16. Limcaoco RSG, Mateos EM, Fernandez JM, Roncero C. Anxiety, worry and perceived stress in the world due to the COVID-19 pandemic. Preliminary results. [Internet] Available at: https:// www.medrxiv.org/content/10.1101/2020.04.03.20043992v1. (Accessed April 30, 2020)

17. Fischhoff B, Wong Parodi G, Garfin DR, Holman EA, Silver RC. Public understanding of ebola risks: mastering an unfamiliar threat. Risk Anal 2018; 38(1): 71-83.

18. Vicario-Merino A, Muñoz-Agustin N. Analysis of the stress, anxiety and healthy habits in the Spanish COVID-19 confinement. Health Sci J 2020; 14(2): 707-712.

19. Kangxing S. Psychological Stress and Gender Differences during COVID 19 Pandemic in Chinese Population. [Internet] Available at:https:/ / www.medrxiv.org/content/10.1101/2020.04.29. 2008406 1v3. (Accessed May 7, 2020) 